\title{
MANAGEMENT OF EXAMINATIONS: ETHICAL ISSUES.
}

\author{
NWEZE. Tina PhD \\ University Counsellor, \\ Ebonyi State University, Abakaliki, Ebonyi State \\ email: drtyna@yahoo.com
}

\begin{abstract}
Examinations occupy a strategic position in our lives and society today.. In a situation where the moral principles, rules and regulations for conducting examinations are truncated by either the teacher or the learner, the validity and reliability of the examination and certification are at risk. The management of examination is something that should be looked into deeply having known the role of examination in our lives. That is the essence of this paper. Talking about the ethical issues, we are all aware of the manner/way in which examination malpractice has eaten deep into the fabrics of our society. Some measures really have to be taken to normalize the examination system in our society. The challenges of examination management are numerous for example, having responsible teachers/examiners, conducive atmosphere for conduction of the examinations, creating in the students, sense of responsibility and good study habit. This paper articulated ethical issues in the management of examinations and stated categorically that it is the wrong handling of examinations that has brought in what some may term examination malpractice or offences or irregularities.
\end{abstract}

Key Words: Examination Ethics, Examination malpractice, Examination Management, Examination Bodies, Schooling, Education.

\section{Introduction}

Education is a fulcrum on which all other developmental facets are hinged (Denga \& Denga, 1998). Broadly speaking, education is an ongoing process that facilitates the process of learning and acquisition of theoretical and practical skills that equip mankind to utilize the environment effectively for personal as well as national development. Proper education has to do with the balanced development of the cognitive (intellectual), affective (emotional/feeling, ethical, moral) and 
psychomotor (practical) domains of an individual not the development of one aspect of the individual at the expense of others.

It is important to always find out the extent the learners have acquired the theoretical and practical skills needed for both personal and national development. The process through which this is ascertained is known as examination. Examination according to Adeyemi and Akindele (2002) is the process, which comes after a period of learning, and it is an organized assessment of an individual's performance, on the basis of his or her institutional procedural exposure. Nsude (1998) avers that examinations are tools intended for the evaluation of the progress made by an individual, in the course of acquiring skills or knowledge over a period.

Examination has to do with the passing of value judgment on an individual, on the basis of the individual's performance in a set of questions, statements or series of tasks given, with the intention of assessing how much of a desired trait, skill or knowledge the individual possesses. In some cases the following terms are used interchangeably to refer to examination: assessment, measurement, evaluation and testing.

As I earlier mentioned, proper education has to do with the balanced development of the cognitive (intellectual), affective (emotional/feeling, ethical, moral) and psychomotor (practical) domains of an individual not the development of an aspect of the individual at the expense of other aspects; this paper is going to emphasize on the ethical issues in the management of examinations.

\section{Historical Development of Test or Examination}

The first written tests were the informal written examinations used by the Chinese to recruit candidates into the civil service (Obimba, 1989; Uche, 2005). The oral examination initiated by Socrates was also informal. In the United States of America before 1815, educational achievement was mainly assessed through oral examination.

In England, Sir Francis Galton, a famous pioneer in the testing movement, constructed tests that clearly demonstrated individual differences in 1869. He also developed statistical procedures to describe them. Karl Pearson, Galton's contemporary developed the Pearson Product Moment Correlation Method, which is useful in prediction and in checking the reliability and validity of standardized tests.

James Cattell who invented the term "mental test" worked on individual differences. He became a pioneer in the American Mental Testing Movement. One of Cattell's students, Edward L. Thorndike made major contributions in achievement testing. 
In France, Alfred Binet and his assistant, Theodore Simons, in 1905 developed a test measuring the intelligence of children. It was an individual intelligence test known as the Binet-Simons Intelligence Test. Lewis M. Terman in America revised the Binet-Simons tests and came out with Stanford-Binet Intelligence Scale, which he published in 1916.

The First World War provided the incentive for the development of group tests. There was this need to assess the intelligence of a great number of soldiers for the purpose of assigning them to different military tasks. A group of psychologists including R.M. Yerkes and A. Otis developed the Army Alpha, a written group test of intelligence, and the Army Beta, an individual non-verbal intelligence test, for this purpose.

David Wechsler developed a series of individual intelligence scales. He first published the Wechsler-Bellevue Intelligence Scale in 1939 to measure adult intelligence. He revised it in 1955 as the Wechsler Adult Intelligence Scale (WAIS). In 1949, he published the second scale known as Wechsler Intelligence Scale for Children (WISC) for ages between five and fifteen years. His third publication was in 1967 when he published the Wechsler Preschool and Primary Scale of Intelligence (WPPSI).

In the area of Standardized tests, George Fisher, an Englishman, developed the first standardized objective test of achievement in 1864. In 1897, J.M. Rice developed in America the Standardized spelling scale also an objective test (Sources, Obimba, 1989; Ifelunni, 1997; Uche, 2005).

\section{Test Organizations in Nigeria}

The systems of education and examination in pre-colonial Nigeria were informal. Fathers taught their sons how to farm and hunt, while mothers taught their daughters how to cook and perform household chores. These they (parents) achieved through allowing their children to follow them always; at first, watching them (parents) perform some duties and later performing some of those duties with their parents and gradually, the parents handing-off and allowing them (children) to perform those duties unaided.

At this time, examinations do come in the form of fathers allotting farmlands to their sons, or in some cases buying local guns for them. The aim is to assess their level of proficiency; this often comes after teaching them the basics of the trade or profession over a period. Mothers were not left behind as they equally examined their daughters' skills by testing their abilities to cook, as well as perform household chores. This they (mothers) achieved by allowing their daughters to take over the roles of mothers in the family. 
At the end of the examination, which is mainly practical, if the child proves that he/she is capable of performing adult roles efficiently, it signifies for the girls that they are ready for marriage and for the boys (though they have to still pass through some rites) for manhood.

With the coming of the colonial masters to Nigeria, the pattern of teaching individuals necessary skills and intended knowledge changed. The colonial masters introduced their style of formal education, which significantly changed our system of education and its method of examination.

Apart from the higher institutions of learning and the various professional examination bodies (that partly conduct their examinations independent of government agencies), the major public examination bodies in Nigeria include:

The West African Examination Council: This body was first established on 31st December 1951 in Gambia, and in Nigeria in 1952, as an examining body for the West African Countries of Gambia, Sierra Leone, Ghana, and Nigeria. Liberia later joined the organization. This council conducts the General Certificate of Education (G.C.E.) examinations at both the advanced and ordinary levels for member countries and equally awards certificates in these examinations.

The Objective Test Unit (OTU) was set up in January 1963 as part of WAEC in Nigeria for the purpose of developing objective test components of the examinations conducted by the WAEC. The Nigeria Aptitude Testing Unit (NATU) was established in 1964 specifically for the development of Aptitude Tests. OTU and NATU merged in 1966 as the Test Development and Research Office (TEDRO), as an arm of WAEC. TEDRO was later renamed the Test Development and Research Unit (TEDRU). The Joint Admission and Matriculation Board (JAMB) was established in 1976 and charged with the responsibility of conducting University Common Entrance Examinations in Nigeria. The International Centre for Educational Evaluation (ICEE) was established and located in University of Ibadan with the charge to offer higher degree programmes in the:

(i.) construction and validation of evaluation instruments;

(ii.) evaluation of educational achievements;

(iii.) evaluation of innovative educational programmes;

(iv.) evaluation of public examinations;

(v.) evaluation of curriculum materials; and

(vi.) evaluation of teaching, learning strategies. 
Other examination bodies in Nigeria include:

(i.) The National Board for Education Measurement (NBEM)

(ii.) National Examination Council (NECO)

(iii.) National Teacher's Institute (NTI)

(iv.) State Ministries of Education

(v.) The National Business and Technical Examination Board.

Apart from the above-named bodies that construct and conduct examinations at various levels we still have the classroom tests or examinations popularly called teacher-made test or informal test. This is a measuring and evaluating technique for the assessment of pupil's learning. Classroom tests are achievement tests prepared by the teacher for his specific class based on what he has taught. The purpose is to measure learning out come.

\section{Importance of Examinations}

The following are the importance of examination(s):

(i) It inculcates the spirit of hard work and the zeal to study in the candidates.

(ii) It affords the authorities the opportunity to ascertain whether or not knowledge has been successfully imparted.

(iii) Makes candidates active participants in teaching cum learning process.

(iv) A teaching method's viability is obtained through examinations

(v) Learning problems and other difficulties encountered by students can be discovered through examination.

(vi) Helps in the identification of students with special skills for placement purposes.

(vii) Examination is a source of data and information for administrative decisions.

(viii) Examination ensures effectiveness on the part of teachers and students in the educational system.

(ix) Examination result is useful in the selection of candidates for employment or educational advancement (placement).

(x) Examination serves as a means of control by the government.

(xi) Examination serves as a means of officially documenting of academic and other capabilities of students.

(xii) Examination results can be used for research purposes.

(xiii) Examination results could also be used for guidance and counselling purposes. 


\section{Forms of Examinations}

1. Written

2. Oral

3. Practical

\section{Types of Examination/Test}

Examination or test is classified into two major types thus:

(i.) Cognitive Ability test, and

(ii.) Non-Cognitive tests.

Under Cognitive Ability Tests we have Intelligence Test (mental ability test), Aptitude Test, and Achievement Test. Cognitive ability tests try to find out how much the learner knows.

The Non-Cognitive Tests are those tests, which try to find out personal qualities and behaviour characteristics of the learner. The information obtained through the administration, collection and collation of these tests are very useful for the purposes of counselling and curriculum planning. The different types of non-cognitive tests or techniques are checklists, projective technique, personality inventory and attitude scale. They assess the affective behaviour and personality of individuals. Non-cognitive tests try to ascertain how the individual thinks, reasons, and feels, his attitudes, interests, values, preferences, personal-social adjustments and other behaviour characteristics.

But for the purpose of this paper, we are going to dwell on the management of achievement tests (examinations or teacher-made tests). Achievement tests are cognitive ability tests, which measure how much the individual has been able to learn from what he has been taught formally, often, in a classroom setting. The results of achievement tests are used for promoting pupils to new classes, and for the awarding of certificates. The certificates obtained are either used for furthering education or securing of a job to earn a living.

\section{What then is Management?}

Collins Concise Dictionary, 21st Century Edition defines management as: the members of the executive or administration of an organization or business; managers or employers collectively; the technique, practice, or science of managing or controlling; the skilful or resourceful use of materials, time, etc; the specific treatment of a disease, etc.

In the context of this endeavour, management refers to the skilful or resourceful use of materials, time, application of appropriate 
technique(s) and practice in the control of examinations in order to achieve a positive result or the set goal.

The teacher or examination bodies may construct the best test or examination, if the examination is not properly managed or handled starting from the time of its construction, packaging, administration, collection, repackaging, marking, scoring, grading and or publishing, the aim of the examination will be defeated. Management of examination becomes a vital issue to be seriously considered if we want our examination result(s) to be both valid and reliable and at the same time to worth its salt. Hence, the crux of the matter - ethical issues in examination management! What then do we mean by ethical issues?

\section{Ethical Issues}

Ethics, according to Collins Concise Dictionary of $21^{\text {st }}$ Century (2001), is a moral principle or a set of moral values held by an individual or group. Succinctly put, ethic is a set of principles that govern good human conduct. Alutu \& Aluede (2005) assert that ethics can simply be defined as laid down guidelines, principles, codes of conduct, rules and regulations guiding behaviour of a group or an organization. Ethical means in line with principles of conduct that are considered correct, especially those of a given profession or group. Ethical issues in this milieu have to do with being decent, fair, good, honest, just, moral, noble, principled, righteous, upright, and or virtuous in the management of examinations.

We know that there are ethical principles guiding everything in life including the management of examinations whether at formal or informal levels. Article 39 of the Teachers' Code of Conduct states that "Teachers should keep all examination records and knowledge at their disposal with absolute secrecy and should not in any manner whatsoever aid and abet examination malpractice by any learners. They are obliged to report all cases of examination malpractice, which come to their knowledge, to appropriate authorities without delay" (Teachers Registration Council of Nigeria, 2005:21). In a situation where the rules and regulations for conducting examinations are not followed either by teachers or learners, this poses a great problem both to the validity and the reliability of the examination results and certification.

For the result of any examination to be authentic, it is expected that:

- The teachers must have taught the candidates well enough to enable them sit for the examination(s).

- $\quad$ The candidate should not be allowed to take an examination in a registered course if his/her attendance is less than 75 per cent. 
- $\quad$ Lateness to examination(s) by either the invigilators/supervisors and or the candidates without valid reason(s) is inexcusable.

- Zero tolerance for impersonation, cheating, leakage of examination questions, bringing in unauthorized aids, collusion with other candidates/examiners/external agents, leaving exam hall without permission, etc.

- The examination hall must be conducive - well ventilated and illuminated, enough chairs and tables for the candidate's comfort should be provided, non-threatening environment, sitting arrangement well spaced, enough examination question papers and answer scripts, proper allotment of time, etc.

- $\quad$ Test construction must be centred on the level of the candidates and must be based on what the examiner has taught the candidates, not out of syllabus experience.

- The examiner must have a matured personality and be responsible, etc.

Taking the afore-stated issues one after the other, can we sincerely say that the teachers have taught their candidates well enough to enable them sit for the examination(s). How many teachers can beat their chest in affirmation and say "of a truth, I have done noble in my profession"? Little wonder you will hardly see the children of those teachers in the schools where they teach. They will prefer sending their children to another school where they feel that there is discipline especially privately owned schools.

How many candidates have been disallowed from taking examination on the ground that his/her attendance is less than $75 \%$ ? Who checks the student's attendance? If the teacher's attendance is less than $75 \%$, what moral justification does he/she have to check the students? How can he keep record? The students too when they come for lectures once or twice without seeing their instructor(s) are discouraged from being regular in class. Besides, when lectures are boring, you see the students playing truancy. Who then do you blame? Your guess is as good as mine.

The issue of lateness to examination by either the invigilators/supervisors or the candidates without valid reason(s) is there. How many defaulters have been called to order? Nobody cares about lateness to examinations. Even if you voice out, you will become a lone voice and an object of either ridicule or attack. No conscience.

The cases of impersonation, cheating, leakage of examination questions, bringing in unauthorized aids, collusion with other 
candidates/examiners/external agents, leaving examination hall without permission are glaring us to the face. When any one is caught doing any of the above, you will be surprised that even your colleagues will come begging you to tamper justice with mercy. One is then left to wonder where the moral principles we preach have gone especially when those who are expected to mould lives get involved in examination malpractice (any doing or act intended to give undue advantage to oneself or another by deceit or fraud before, during or after an examination that warrants the application of appropriate actions against the alleged guilty offenders). People throw caution to the wind. Integrity no longer counts so to say as those with integrity are seen as wicked teachers who do not want their candidates to either graduate or go with good grades.

Getting into the examination hall(s) leaves one with nothing desirous. The hall is not conducive, not well - ventilated and illuminated. No enough chairs and tables for candidates' comfort. The examination hall is jam-packed to the extent that those who under normal circumstances would not have loved to cheat are tempted to do so because the atmosphere is not conducive.

To buttress the afore-stated, examination question papers and answer scripts are not sufficient sometimes. Where candidates are made to share question papers - what do you expect? What about time allotment? Sometimes, time allotment is not proper. We either under or over allot time. Either of the two is not good and consequently will lead to problem(s) in the said examination.

It is expected that test construction be centred on the level of the candidates and be based on what the examiner's have taught the candidates, not out of syllabus experience. What do you say of a teacher who has not taught his candidate but sets examination for such a one? Sometimes some teachers are too busy with extra-curricular activities and their personal business as well, that they do not really have the time to impart the knowledge on the candidates and they just muddle things up. Some are not organized hence when they enter classroom, they are checking their time piece per minute or at best, they engage in story telling instead of teaching their candidates and once their time is over, they sigh a sigh of relief and quickly rush out of classroom.

The worst is that, some of the examiners are not responsible and have no mature personality. Hence, they could belittle themselves by sale of grades either for cash or for kind. What of parents and highly placed individuals in the education sector who are guilty of perpetuating examination malpractice? All these, tend to leave one wondering where the moral principles guiding the conduct of examination have gone to? 
It is the wrong handling of examinations that has brought in what some may term examination malpractice or examination offences or examination irregularities. In a lamentation over the Nigerian Education, Denga and Denga (1998:6) succinctly put the ethical and moral problems in a poetic way starting from the rise and fall and ended it with a ray of hope thus:

The Nigerian education system, when born was a virgin; no corruption or pollution. The great men and women we have today were her products. It is a pity that the increasing rate of malpractice has tarnished her quality. In all, we are hoping and believing that there are men and women who will take the bull by the horn and confront these ills in the education system so as to rehabilitate and reform the Nigerian education system (Paraphrased).

The problem lies in the fact that:

- Not everyone who is in the classroom is a professional teacher and as such, might not know the ethics of the teaching profession.

- Sequel to the above issue is that one cannot implement what he/she is ignorant of.

- The pervading emphasis on grades and certificates in the society have made some examiners, parents and candidates to throw caution to the wind in a bid to have a high score for either to increase the reputation of school or their candidates' chances of securing good job in the labour market.

- Low moral standards in the society.

- Poverty on the part of teachers who constitute the chunk of invigilators and examiners.

- A tenuous legal process to punish offenders.

\section{Challenges of Examination Management in Nigeria:}

Every profession has her ethics which is the moral principles guiding the practice of such a profession. Teaching as a profession has her moral principles guiding the conduct of the members of this noble profession. It is worth noting that the management of examinations could be very easy. But before this is achieved, the teacher must have developed a mature personality first as a teacher and later as an examiner.

The teacher must follow the following principles of responsible classroom management as proposed by Queen, Blackwelder \& Mallen (1997):

(i) To have responsible students, teachers must be responsible. 
(ii) Teachers state instructional objectives clearly.

(iii) Responsibility is taught and incorporated instructionally throughout the school year.

(iv) The classroom environment is warm and inviting.

(v) Instruction is interactive, and student classroom participation is high.

(vi) Standards and guidelines replace rigid school and classroom rules.

(vii) Children are treated fairly but not always disciplined in the same manner.

(viii) Consequences are used to teach students to self-correct inappropriate behaviours and to assume responsibility for their actions.

(ix) Students performance and responsibility are encouraged and acknowledged. Bribery and predetermined rewards are not used.

(x) Students practice internal behaviour control rather than having their behaviour controlled externally.

The classroom must be managed well first before examination period. Since a large chunk of schoolwork a student does is reading, it becomes pertinent for students to be taught how to study (Nweze, 2007). This should be incorporated in each subject. Observation has shown that many students read textbooks the same way they read a short story, novel or notebook. They start with the first word on the first page and read straight through until they come to the last word of the material they are reading. The emphasis being made is that novels, notebooks, textbooks or magazines have different methods in terms of the way to read and study them.

The onus lies on the teachers to make adequate effort in inculcating in the students proper study skills. For instance, the way of reading textbooks is what many authors have called the SQ3R method (Nweze, 2007).

$\begin{array}{lll}\text { S } & - & \text { Survey } \\ \text { Q } & - & \text { Question } \\ \text { R } & - & \text { Read } \\ \text { R } & - & \text { Recite } \\ \text { R } & - & \text { Review }\end{array}$


Survey means to read the chapter title and all of the section headings. Summary paragraphs and any review questions at the end of the chapter are to be read before the entire work is read. This gives the reader a good idea of what the reading is going to be within a very few minutes.

Question - The reader is expected to turn the heading into a question. This enables him to be specific on what he is trying to find out when he/she starts reading.

Read - Now read the section to find the answer to your question.

Recite - First ask yourself the question about the section that you have just read; then tell yourself the answer that you have learned from your reading.

Review - When you have finished the question, read and recite steps for all the sections in your assignment, then it is time to Review. Cover up your text or note, repeat the questions in step two and see whether you will be able to answer them correctly. Where you are not able, refer back to the material read. Review takes very few minutes and gives you another chance to make sure that you have learned the material.

The issue being raised here is that, if from day one students are taught to be responsible and to acquire proper study skills, management of examinations will be easier especially if the examiner has a mature personality. But most often, the teachers and managers of these examinations do not perform their own assignment (duty), which in turn enhances candidates' disobedience. Until our obedience is complete, we cannot expect much from our students. This is the crux of the matter, which must be faced with zeal and seriousness. The major challenge therefore lies in our ability to inculcate the right values in the teachers/managers of examinations who in turn should model the right attitude to both classroom work and examination to the students. Until this is done, the management of examinations will continually erode solution.

\section{Summary}

Examinations occupy a very strategic position in our lives (educational and industrial) today. Teachers and counsellors rely on them for a comprehensive evaluation of their students and clients. To decide whether or not a student merits being promoted to another class, a series of achievement tests that will eventually culminate in a well-founded decision has to be given. In the industrial setting, experts in human 
relations and employment bureaux utilize tests in reaching a decision as to the employability of an individual applicant. Tests are still used in appraising certain individuals in our national life even after employment.

Since examinations occupy such a central position in our educational and industrial settings, management of examinations should not be taken lightly. Every effort must be made to properly harness every resource (both human and material) needed in order to achieve the objective(s) of examinations in the school system. Management of examinations should start with creating in the students, sense of responsibility from day one and also teaching them proper study skills and helping the teachers and the managers of examinations and all stakeholders to develop mature personality. When these are imbibed, management of examination will become very easy as both the invigilators and the students will no longer struggle to abide by the principles governing examinations.

\section{References}

Adeyemi, J. \& Akindele, I. (2002). Examination Malpractices in Nigeria Educational System: Causes, Effects and the Way Out. Nigerian Journal of Clinical and Counselling Psychology, 14(1).

Alutu, A.N.G. \& Aluede, O.O. (2005). The Role of Counselling in dealing with Examination Malpractice and Ethics. Revisita esparola. De orientacion y pscio pedagogia Spain 16 (2) 188 - 197.

Collins Concise Dictionary. 21st Century Edition (2001). Glasgow: Harper \& Collins Publishers.

Denga, D. I. \& Denga, H.M. (1998). Educational Malpractice and Cultism in Nigeria. Calabar: Rapid Educational Publishers Ltd.

Ifelunni, I.C.S. (1997). Psychometric and Ethical Considerations in Counselling. Enugu: Auto Century Publishing Company Limited.

Nsude, I. (1998). Principles and Practice of Education (Education I). Enugu: Hillys Press Nigeria Ltd.

Nweze, T. (2007). Crisis in Literacy: The Way Out. In Journal of Applied Literacy and Reading (3)Special Edition p.232-237.

Obimba, F.U. (1989). Fundamentals of Measurement and Evaluation in Education and Psychology. Nigeria: Totan Publishers Limited.

Queen, J. A., Blackwelder B.B., \& Mallen, L.P. (1997). Responsible Classroom Management for Teachers and Students. New Jersey: Prentice-Hall Inc.

Uche, O.S. (2005). National Disgrace: Examination Malpractice. Enugu: Onyigbuo Steven Uche. 